\title{
Interconnecting Race and Gender Relations: Racism, Sexism and the Attribution of Sexism to the Racialized Other
}

\author{
Lavinia Gianettoni • Patricia Roux
}

Published online: 24 February 2010

(C) Springer Science+Business Media, LLC 2010

\begin{abstract}
This article analyzes the way that attitudes about gender and race relations are interconnected. Based on a survey study conducted in Switzerland with a sample of 273 Swiss nationals (125 men and 148 women), it shows that the attribution of a higher level of sexism to "racialized Others" than to Swiss individuals is a racist process resulting in the justification and naturalization of the ordinary Swiss sexism seen in the gendered division of labor. However, this study also shows that the attribution of a higher level of sexism to the Other can be countered by simultaneously adopting both feminist and non-racist attitudes.
\end{abstract}

Keywords Sexism $\cdot$ Feminism $\cdot$ Racism $\cdot$ Interconnecting hierarchical social relations

\section{Introduction}

This research draws on the sociology of gender (Guillaumin 1995; Delphy 1984, 2008) and an intersectional perspective anchored in Black feminism and postcolonial studies to analyze the ways in which attitudes about gender and race relations are interconnected. These hierarchical relations and their effects structure all societies and are embedded in the relationship between the West (European and North American countries) and the East (the rest of the world, perceived as "Other" by the West). The results of this study,

L. Gianettoni $(\bowtie) \cdot$ P. Roux

Institute of Social Sciences,

Faculty of Social and Political Sciences,

University of Lausanne,

Bâtiment Vidy, CH-1015,

Lausanne, Switzerland

e-mail: Lavinia.Gianettoni@unil.ch therefore, while based on a Swiss sample, reveal processes that are relevant to many Western countries.

Our research analyzes the interconnection between gender and race relations by examining a topic that strongly influences the current debate about immigration in Switzerland and other European countries: the sexism of immigrants. In this debate, the sexism of immigrants, or the sexism of the Other, is seen to be an intrinsic characteristic of the immigrants' culture, which is understood to be radically different from Swiss culture. The notion of "cultural difference" is mobilized as a justification for political measures that restrict immigrants' rights. Moreover, the exaggeration of cultural difference is a form of modern racism that contributes to perceptions of a dichotomy between Switzerland, a presumed model of gender equality, and the Other, who is seen to be intrinsically sexist.

These concerns about the way notions of gender and race impact debates about immigration politics led us to formulate two main hypotheses that are tested in this survey study. Hypothesis 1 states that the attribution of a higher level of sexism to racialized foreigners who are understood to be different from the Swiss people - the Other-is a racist process that minimizes and therefore reinforces the ordinary sexism that structures Occidental countries like Switzerland. Hypothesis 2 states that the attribution of a higher level of sexism to the Other is a process that can be countered by simultaneously adopting both feminist and non-racist attitudes.

Our study was conducted with a sample of Swiss men and women from diverse socio-economic and age groups. First, we will present the theoretical background concerning the process of the construction of the Other. After presenting our operational definitions of racism and sexism, we will adopt an intersectional perspective in order to develop the idea that common understandings about the 
sexism of the Other both contribute to the construction of racialized Others and maintain the gendered organization of hierarchical relations. Next, we explore the way this process can be countered through the adoption of critical positions on gender and race relations.

\section{Hierarchical Relations and the Construction of the Other}

Social categorization forms the basis for all representations of social reality, collective behavior (Tajfel 1978), social interactions (West and Zimmerman 1998), and structural organization within social relations (Delphy 1984; Guillaumin 1995). Many different characteristics can be used to categorize individuals (e.g., gender, skin color, eye color, and height), but only some criteria become socially relevant. Gender and race/ethnicity are two socially significant criteria that divide the world into dichotomous, arbitrary, and hierarchical categories (Delphy 1984). The process of gender and race division is an instrument of domination (Guillaumin 1995) because it "invents Others" (Delphy 2008) and constructs Others as groups (women, Blacks, non-nationals, etc.). The result is a hierarchy between the dominant individuals who control this process (men, Whites, nationals, and so on) and the dominated groups generated by this process. The dominants are not perceived and not aware of themselves as a specific group but instead are seen as a universal point of reference (see also Hurtig and Pichevin 1991). In race relations, as in gender relations, the dominant have the power to classify, to name, and therefore to "construct the Other" (Delphy 2008).

\section{Race Relations and Racism}

National, cultural, religious, or ethnic affiliations are all hierarchical criteria of categorization that underlie race relations. These social relations bring "color" groups into opposition (such as Whites and Blacks), but also set up an opposition between nationals and all immigrants to Western nation-states (for example, the Swiss and the foreigners). Following the work of Colette Guillaumin (1972), we define racism as an institutional and ideological system that prescribes race relations and legitimizes the superiority of some groups (defined by criteria such as ethnicity or nationality) over others. Guillaumin named this hierarchical aspect of race relations "altero-referential racism" (1995). This term reflects the fact that racialized groups are constructed as Others, as different from the dominant groups (Whites, native citizens, and so on). In addition, racialized groups are essentialized; their behaviors and ways of life are seen as being determined by their places and cultures of origin.
This definition is similar to the concept of "subtle" racism proposed by Thomas Pettigrew and Roel Meertens (1993, 1995). In contrast to a more direct (blatant) racism that explicitly expresses its disdain for the Other, subtle racism is manifested by an attitude that seeks to exaggerate cultural differences, hesitates to attribute positive qualities to foreigners, and defends traditional values of the Nation. The subtle racism scale was tested in several studies conducted in Western Europe (including France, Germany, Great Britain, and the Netherlands). The research presented in this article relies upon this definition of racism, while adapting it to the political context of immigration in Switzerland (to understand the Swiss context in comparison with other countries, see, for example, Bülent 2005; Giugni and Passy 2006; Wicker et al. 2003). We chose to focus on subtle racism because the "difference of the Other" and the protection of national identity are common arguments in debates about immigration. In particular, immigrants are seen to have difficulty integrating and such problems are treated as a menace to Swiss national culture and values. In the current political context, "cultural differences" and the "values of the Other" are perceived as threats, and therefore individuals do not associate racism with belief in these differences. However, these perceived differences justify the stigmatization of immigrants and the adoption of coercive measures. In Switzerland, this process of hierarchical differentiation works in particular to mark Muslims as different (Stolz 2005). We considered this fact when measuring the racism expressed by the individuals who participated in our study.

\section{Gender Relations and Sexism}

Analogous to racism, we define sexism as an institutional and ideological system that prescribes division by gender, differentiates the social roles attributed to women and men, and ranks them in a hierarchy. In this "system of gender" (Delphy 2001), biological sex serves as a criterion for categorization and differentiation; this criterion is foundational to our gendered social order. A process of social differentiation accompanies the process of biological differentiation into sex categories (Mathieu 2000). Men and women are assigned specific positions and gender roles: men and masculinity are associated with productive activities and the public arena (politics, remunerative work, etc.), while women and femininity are associated with reproductive activities and the private sphere (family, care, etc.). This division of labor based on gendered distinctions between public and private, or masculine and feminine, constitutes the material basis for patriarchy (Delphy 1984). Thus, for example, domestic work is not remunerated (or if it is paid, it is underpaid) and, within the labor market, women occupy less socially and economically valued 
positions than men (Jenson et al. 2000). In Switzerland, the gendered division of labor is a dominant practice that includes all social classes (SFSO 2008). At the same time, however, gender equality is a principle proclaimed by democratic societies (Roux 2008) and is formalized in a multitude of constitutions and laws.

To analyze this normative ambivalence between inegalitarian practices and egalitarian principles, our study operationalized the concept of "naturalization" developed by Guillaumin (1995). The process of naturalization leads to the belief that gender differences and gender inequalities are not socially constructed but are the result of natural differences between men and women. Gender is not perceived as a social system organizing the positions attributed to men and to women in public and private spheres, but as a "question of nature"; for example, it would be part of the "nature of women" to occupy tasks related to reproduction (Guillaumin 1995). The process of naturalization justifies gender inequality because it allows individuals to believe that gendered behaviors and relations are fixed and therefore legitimate and impossible to change. In our study, sexism based upon the naturalization and immutability of gender relations is considered to be an "ordinary" day-to-day sexism (Delphy 2006).

Earlier studies have consistently shown that men justify strongly than women the gender system that place them in a dominant position; men adhere more strongly to sexism than women (e.g., Campbell et al. 1997; Glick and Fiske 2001) and women endorse affirmative action more strongly than men (Crosby et al. 2006). Similarly, a recent representative Swiss survey has shown that men denied gender inequalities and minimized ordinary sexism more than women (Staerklé et al. 2007). In the study presented in this paper, we expect to obtain similar results regarding differences in men's and women's views of ordinary sexism: men should strongly defend the gender system that place them in a dominant position by naturalizing the gendered division of labour.

\section{Parallels and Intersections Between Racism and Sexism}

Based on what we have presented above, it is clear that a comparable process regulates both gender and race relations: categorization based on criteria of gender and race leads to the division and hierarchization of the groups it produces. These processes of categorization, division, and hierarchization result in sexist and racist attitudes. Though processes regulating hierarchical social relations (racism and sexism) are relatively well understood, there nevertheless remains a theoretical vacuum regarding the ways in which these relations are interconnected. Mainstream gender research fails to include concerns about race and race research fails to include concerns about gender (Reid and Comas-Diaz 1990). Analyses of racism and sexism are usually developed in separate research programs or in order to establish parallels (e.g., Swim et al. 1995).

However, over the last 30 years, racialized women have developed new approaches to study interlocking systems of domination (most notably racism and sexism). The first analyses of this kind emerged from Black feminists (Combahee River Collective 1979; Hooks 1981; Hull et al. 1982; Morraga and Anzaldua 1983) who criticized the sexism inherent in the U.S. Civil Rights Movement of the 1960s and the racism of the dominant (white) feminist movement of the 1970s. They argued that, by focusing only on one form of domination and discrimination (racism or sexism), these movements contributed to supporting a "matrix of domination" (Collins 2000). Responding to a focus that neglects many other forms of inequalities (e.g., the invisibility of the doubly dominated, or "intersectional invisibility," [Purdie-Vaughns and Eibach 2008]), feminist researchers adopted an intersectional approach (Crenshaw 1994). This approach analyzes the mutually constitutive relations among hierarchical social identities such as those based on gender and race. The fundamental idea behind this approach is that any individual occupies different positions in different hierarchical systems; for example, a black man occupies a dominant position in terms of gender relations and a dominated position in race relations. This matrix of domination must be studied by taking into account the multiple interlocking hierarchical systems.

Following this approach, some recent research has investigated the impact that being situated at the intersection of these different hierarchical systems has on individual self-esteem (Buckley and Carter 2005; Settles 2006). Others have analyzed stereotypes of people situated at this intersection and the impact of these mutually constituted images on forms of discrimination (Collins 2000; see also, for a study with survey data, Steinbugler et al. 2006). This study offers an analysis of the way attitudes about gender and race are interconnected. More precisely, we adopt an intersectional perspective anchored in Black feminism and postcolonial studies that takes into account the way systems of race and gender (racism and sexism) are more broadly inscribed in the relations of social domination of the West over the East, or of the North over the South.

\section{The West as a Model of Gender Equality} and the Attribution of Sexism to the Other

Despite persistent gender inequalities in Switzerland, as in other democracies, gender equality is not merely a normative principle in laws and regulations but forms a common element of popular thought beyond political divisions (Roux et al. 1999). Multiple scholars from diverse 
disciplinary backgrounds such as anthropology (Nader 1989) and law (Volpp 2000) have shown that the principle of gender equality is especially salient in the comparisons of Western and non-Western populations or countries. Particularly with respect to their customs regulating relations between women and men, immigrants from outside of Europe, especially Muslims, are stigmatized as jeopardizing "the cultural integrity of the national community" due to their adherence to "archaic" values and traditions (Stolcke 1995).

In Switzerland, the machismo of Muslim men and the submissiveness of Muslim women are regularly featured in the media as well as in the political debate about Muslim integration. In this debate, gender equality is overemphasized and integration is presented as a problem that endangers Swiss national culture and values. For instance, in 2008, the Federal Office for Migration (www.bfm.admin.ch) published a "guide to the application of the convention about integration" (see the new federal Loi sur les étrangers, or Law Regarding Foreigners) in which it proposed that cantons organize integration courses to allow immigrants "to familiarize themselves with Switzerland, its peculiarities and customs, and also with current norms, rights and duties of its citizens, its principle of equality between men and women, its health system, etc." (emphasis added). This prioritization of the principle of equality implies two points that form the basis for our research agenda: if immigrants must familiarize themselves with gender equality, it is because they are perceived to have little or no respect for it, and if Switzerland makes equality "its principle," it is because it conceives of itself as more egalitarian than the countries from which immigrants originate.

Another example of this ethnic reading of gender comes from the way in which collective rapes committed by immigrants are condemned in Switzerland as well as in France. Young aggressors are believed to commit rape as a result of their intrinsically sexist culture, which is associated with national origin (Hamel 2003). According to this interpretation, the aggressors are proof of a stronger or, to use Christine Delphy's term (2006), an "extraordinary" and specific sexism. This extraordinary sexism has nothing in common with the "ordinary sexism" that organizes gender relations in the rest of Western society (e.g., through domestic violence) or with the sexism of native French or Swiss rapists. Through a process of generalization and homogenization, all young offspring of parents from the Maghreb (in France), from the former Yugoslavia (in Switzerland), all Muslims, and even all foreigners are suspected of acting to upset the norm of gender equality for which the West is seen as the guarantor. Sexist discrimination would then be nothing more than a reality that comes from "elsewhere" and that belongs to the racialized Other. This represents a process of "ethnicization" of sexism (Roux et al. 2007).
Based on this earlier research, we hypothesized that the attribution of a higher level of sexism to a racialized Other is a racist process that participates in the minimization of ordinary sexism and thereby legitimizes it. In a Western context, denouncing the sexism of the Other is a way to make invisible the hierarchical gender relations in which everybody is embedded. This also preserves the ideal of equality present in democratic societies without demanding concrete efforts to realize this ideal. At the same time, this denunciation justifies the effects of Othering processes such as the stigmatization of and discrimination against racialized groups.

We do not make specific predictions about gender differences that might occur in the relation between racism, ordinary sexism, and the perception of sexism in the Other. We expect that both men and women who adhere to subtle racism by considering immigrant culture and values to be too different from their own will attribute more sexism to the Other than to the Swiss and minimize the ordinary sexism structuring gender relations in Switzerland. Nevertheless, since Swiss men occupy a dominant position in both gender and race systems and Swiss women occupy a dominant position only in the race system, we will investigate whether and how these relations are moderated by gender.

\section{Feminism, Racism and Intersectional Political Consciousness}

In the context of presumed Western superiority regarding gender equality, categorization based on race becomes interconnected with categorization based on gender. When gender equality is evoked in the comparison of groups that are constructed according to a principle of racial division, gender categorization provides content for differentiation and the creation of hierarchy based upon race. It is because the Other regulates gender relations so poorly (i.e., because he is sexist) that he is "too different." Consequently, he has no place in Switzerland or, more generally, in the West. In this understanding, the criteria of hierarchical categorization, gender and race, are simultaneously operative and interconnected. This racialization of sexism plays a central role when people have to evaluate the legitimacy of women's politics concerning the Other, as in the case of the French law forbidding the headscarf in schools. The law has been justified at the political level in the name of gender equality, i.e., the need to protect Muslim girls from patriarchal Islam. However, it has been shown that for ordinary White non-Muslim men and women, the support of this law is explained by racist attitudes and not at all by feminist inclinations. In other words, the more individuals adhere to a racist ideology, the more they support the law (Roux et al. 2006). In sum, these results show that when Occidental men and women evaluate the sexism of the 
Other, their judgments are determined by racism and not by feminism. These findings lead to an important question: as a member of a Western society who thereby occupies a dominant position in race relations, how does one criticize sexism whose victims are racialized women without falling into the trap of racism? More specifically, how should we position ourselves, as Western feminists, with respect to the sexist discrimination experienced by racialized women?

Similar questions have been addressed by Ronni Michelle Greenwood (2008), who asked how feminists could unite themselves when race relations structure activist groups. Her results showed that solidarity in an ethnically heterogeneous group is made possible by the development of an intersectional political consciousness. This is defined as the consciousness of the consequences of multiple intersecting identities, such as the disadvantages associated with being a woman and the privileges associated with being White. Greenwood and Christian (2008) have shown that White non-Muslim women primed with intersectional consciousness report more accepting attitudes towards Muslim women wearing headscarves. Following this line of research, we hypothesize that Occidental men and women without a sensibility that links racism and sexism risk falling into the trap of racism; this trap involves the attribution of an extraordinary sexism to the Other and the corresponding neglect of ordinary Western sexism. Therefore, our second main prediction states that a feminist attitude must be coupled with a non-racist attitude to avoid the bias of focusing upon the extraordinary sexism of the Other without taking into account the ordinary sexism that potentially victimizes all women. Even if women should express more feminist engagement than men as a way to fight against the gender system that place them in a dominated position, we expect that both men and women who simultaneously adopt feminist and non-racist attitudes likely will not differentiate ordinary sexism from the perceived sexism of the Other. We will nevertheless investigate whether gender moderates our results.

\section{Hypotheses}

This study examines two main hypotheses. One hypothesis states that the attribution of a higher level of sexism to a racialized Other is a racist process that contributes to the naturalization and justification of ordinary sexism (Hypothesis 1). We expect that women will adhere less to sexism than men, but we do not expect specific gender differences in the link between racism, ordinary sexism, and the sexism of the Other. We nevertheless will explore whether the racist process of Hypothesis 1 is moderated by gender.

Our second main hypothesis states that the attribution of a higher level of sexism to the Other can be countered by adopting both a feminist and a non-racist attitude (Hypothesis 2). Even if we expect women to adhere more strongly to feminism than men, we do not expect specific gender differences to be seen in the interaction between feminism and racism.

\section{Method}

This study used a questionnaire that was divided into two distinct parts. In the first part, we used a correlational methodology to explore the link between racism and ordinary sexism and the way in which Other sexism mediates this relation (Hypothesis 1). In the second part of the study, we adopted an experimental methodology to test Hypothesis 2.

\section{Participants and Procedure}

Participants included 273 Swiss nationals (148 women and 125 men) living in French-speaking Switzerland. They were between the ages of 16 and 89 years $(M=38.01 S D=$ 15.91) and were recruited in 2006 by students enrolled in a gender studies seminar. Each student was required to find 15 respondents among his or her friends and family. Students were asked to recruit individuals from a variety of social backgrounds and age groups. As a result, respondents represented a range of socio-economic statuses, although high status respondents were over-represented (29.6\% of respondents had obtained an apprenticeship certificate, $36.3 \%$ had middle-level education, and $34.1 \%$ had university-level education). The standardized questionnaire was anonymous; respondents completed the questionnaire at home and sent it to us through the mail.

Gender and age were independent from each other, but gender was significantly correlated with education level; a university-level education was over-represented among men. Therefore, all the following analyses were performed with and without educational level as a covariate. Since the results did not vary significantly, we will present data from the analysis performed without educational level as a covariate.

\section{Materials}

The first part of the questionnaire was composed of a series of items measuring racism, ordinary sexism, Other sexism, and feminism. All questions were asked in French and allowed for six possible responses: 1= pas du tout d'accord (completely disagree), $2=$ pas d'accord (disagree), $3=$ plutôt pas d'accord (moderately disagree), $4=$ plutôt d'accord (moderately agree), $5=$ d'accord (agree), and $6=$ tout à fait d'accord (completely agree). All of our measures 
are presented in Appendix A. They were developed and submitted in French and have been translated into English for this paper (see Appendix B for the original French scales and questions).

The second part of the questionnaire began with a vignette about forced marriage in which we varied the origin (African vs. Swiss) of the parents compelling their daughter to marry. This vignette was followed by a series of questions measuring the sexism attributed to the family (using a 6-point scale; see appendix). Since our objective was to compare judgments about a dominated Other to judgments about the dominant Western referent, it was necessary that our respondents had no doubt about the social position of the protagonist family in the vignette. Thus, in this experimental procedure, the two versions of the vignette juxtaposed acts of sexist violence (forced marriage) committed either in an "African Muslim" family or in a "relatively wealthy Genevan" family. The first version presented a heavily stigmatized category in Switzerland representing a racially dominated group, whereas the second version presented a clearly dominant category. One hundred and thirty-two persons (68 women and 64 men) responded to the "African family" version, while 141 individuals (80 women and $61 \mathrm{men}$ ) responded to the "Swiss family" version (the vignettes are presented in Appendix C).

\section{Measure}

We constructed a 4-item racism scale to measure the independent variable for Hypotheses 1 and 2. It was inspired by the subtle racism scale developed by Pettigrew and Meertens (1993 for the French version/1995 for the English version) and adapted to take into account the political debate regarding the integration of foreigners in Switzerland. As suggested earlier, judgments about the culture and values of the Other (arguments included in the subtle racism scale) are part of the altero-referential racism that constructs immigrants as different, essentializes them, and renders them responsible for "their difficulties of integration." Our measure of subtle racism takes into account these dimensions (see also Roux et al. 2007). Items were preceded by an introductory question: "In your opinion, why have certain immigrants in Switzerland faced difficulties in integrating themselves?" An example of an item was: "It is because their values are too different from predominant Swiss values." Each item was evaluated on a scale of 1 (completely disagree) to 6 (completely agree). The scale showed good internal reliability (Cronbach's $\alpha=.81$ ).

Ordinary sexism, the dependent variable in Hypothesis 1 , was assessed by a 6-item scale (Cronbach's $\alpha=.83$ ) based on certain concepts from feminist materialist sociology (Guillaumin 1995). This scale (already used in previous studies, Roux et al. 1999) measures the justification and naturalization of the gendered division of labor prevalent in Switzerland today. The introductory question for this area was: "Numerous sociological studies have shown that it is predominantly women who care for children and households. What are the explanations, as you see it, for this situation?" An example of an ordinary sexism response was: "It is because it is more natural for a woman than for a man to take care of children and the household" ( $1=$ completely disagree to $6=$ completely agree).

A feminism scale, used to measure the independent variable in Hypothesis 2, was composed of three questions (Cronbach's $\alpha=.75$ ) developed on the basis of previous research (Roux et al. 2006). An example representative of the questions asked to measure this factor was: "In daily life, do you think you fight, in your own way, against inequalities between men and women?" $(1=$ no, not at all to 6 = yes, completely).

A measure of sexism of the Other, the mediation variable in Hypothesis 1, was developed for this study. Two items allowed us to construct this indicator: 1) "Sexism is still highly present in Switzerland" and 2) "However, sexism is less strong in Switzerland than in other countries, notably the countries of the South" $(1=$ completely disagree to $6=$ completely agree). The first item was subtracted from the second in order to measure the level of sexism attributed to the Other in comparison with Swiss people. The subtraction of "Swiss sexism" from "more sexism of the Other" permits us to take into account the relationship between the minimization of Swiss sexism and the attribution of a stronger sexism to the Other. A negative score corresponded to the acknowledgment of Swiss sexism as at least as strong as Other sexism $(\min =-4)$ while a positive score corresponded to the attribution of a stronger sexism to the Other and the minimization of Swiss sexism $(\max =+5)$.

After reading the vignette, the respondents answered a general control question about the acceptability of forced marriages: "To what degree do you think it is acceptable or not for parents to impose this marriage upon their daughter?" (1=completely unacceptable to $6=$ completely acceptable). This control question allowed us to verify that forced marriages were perceived as a problematic practice in both the African and Swiss conditions. After this question, the participants were invited to evaluate the sexism of the family. The dependent variable family sexism was measured with a 4-item scale (Cronbach's $\alpha=.72$ ). We developed items that reported beliefs that are very common in the debate about Muslim integration and about the control of women by men in Islam. The items were introduced in this way: "In your opinion, if we compare this type of family to others, can we say that:" and participants were then asked to evaluate several statements such as "In this type of family, women are less emancipated 
than others" $(1=$ completely disagree to $6=$ completely agree).

\section{Results}

Preliminary Analyses

Tables 1 and 2 present descriptive statistics and intercorrelations for all of our measures; data are presented separately for men and women. Participants moderately agreed with racist items $(M=3.86, S D=.93)$, while, on average, they disagreed with ordinary sexism $(M=2.86, S D=1.01)$. The global mean of feminism was very close to the mid-point of the scale $(M=3.51, S D=.99)$. Respondents globally attributed a stronger sexism to the Other than to the Swiss $(M=$ $0.69, S D=1.72)$. The gender of the respondents had no significant impact on racist attitudes but did have a significant effect on feminism, ordinary sexism, and the attribution of sexism to the Other. As expected, women adhered more to feminist attitudes than men $(F(1,271)=$ $18.15, p<.001)$ and rejected ordinary sexism more strongly than men $(F(1,271)=4.82, p<.05)$. Finally, results showed that men attributed more sexism to the Other than did women $(F(1,271)=3.90, p<.05)$

Concerning the vignettes, the control measure indicates that participants uniformly judged forced marriage to be an unacceptable practice $(M=1.53, S D=.89)$; such judgment was independent of the version presented: $M=1.46, S D=.90$ for the Swiss version and $M=1.60, S D=.87$ for the African version, $F(1,270)=1.65$, n.s. The gender of respondents had a marginal impact on this control measure: $M=1.64, S D=.96$ for men and $M=1.44, S D=.81$ for women, $F(1,269)=3.49$, $p<.07$. Respondents generally acknowledged the sexism of the family $(M=4.36, S D=.79)$, even if they did so more with the African family (specific results are reported and commented on below). The gender of respondents did not have a significant impact on this indicator $(F(1,271)=0.29$, n.s. $)$.

Table 1 Descriptive statistics by gender.

\begin{tabular}{|c|c|c|c|c|c|c|}
\hline \multirow[t]{2}{*}{ Variable } & \multicolumn{2}{|l|}{ Men } & \multicolumn{2}{|c|}{ Women } & \multicolumn{2}{|l|}{ Total } \\
\hline & M & $\mathrm{SD}$ & M & SD & M & $\mathrm{SD}$ \\
\hline Racism & 3.90 & .99 & 3.82 & .88 & 3.86 & .93 \\
\hline Ordinary sexism & 3.00 & 1.02 & 2.73 & .99 & 2.86 & 1.01 \\
\hline Sexism of the other & .92 & 1.88 & .51 & 1.55 & .69 & 1.72 \\
\hline Feminism & 3.24 & 1.00 & 3.73 & .92 & 3.51 & .99 \\
\hline Family sexism & 4.33 & .79 & 4.38 & .78 & 4.36 & .79 \\
\hline
\end{tabular}

6 -point scale $(1=$ not at all to $6=$ totally) for all variables except "Sexism of the Other" (range from -4 to +5 )
Racism was positively correlated with ordinary sexism and sexism of the Other and was negatively correlated with feminism for both women and men respondents. Moreover, the more men and women adhered to ordinary sexism, the more they attributed a stronger sexism to the Other and the less they expressed a feminist position. Results also show that the attribution of sexism to the Other was negatively correlated with feminism for both women and men. Finally, a difference appeared between men and women concerning the attribution of sexism to the family described in the vignettes: for men, racism and sexism of the Other were positively correlated to the acknowledgment of family sexism, while these relations were not significant for women.

Ordinary Sexism and Racism: The Mediating Role of the Attribution of Sexism to the Other

To test Hypothesis 1, according to which racism would reinforce ordinary sexism by attributing a higher level of sexism to the racialized Other, a mediation analysis was performed (Baron and Kenny 1986). To confirm our hypothesis, we would expect to find that racism predicts ordinary sexism and that this relation is mediated by the attribution of sexism to the Other. To establish this mediation, linear regression analyses should show that the independent variable (racism) has a significant effect on the dependent variable (ordinary sexism) and on the mediator (attribution of sexism to the Other). When controlling for the mediator, the effect of the independent variable on the dependent variable should be significantly reduced. We performed these analyses separately for men and women. Since the results were very similar (both mediations were significant), we present the results of the analysis including both women and men (see Fig. 1).

Results show a strong link between the independent variable (racism) and the dependent variable (ordinary sexism): the more respondents considered the Other to have a culture that is too different from that of the Swiss, the more they justified the naturalized gender division of labor $(B=.419, S E=.061, t=6.90, \beta=.39, p<.001)$. The link between the independent variable (racism) and the mediator (sexism of the Other) was also significant $(B=.785, S E=.102$, $t=7.73, \beta=.43, p<.001)$. When the mediator was included in the regression, the link between the mediator and the dependent variable was significant $(B=.170, S E=.035, t=$ 4.90, $\beta=.29, p<.01)$ and the link between the independent variable and the dependent variable significantly decreased $(B=.285, S E=.064, t=4.46, \beta=.26, p<.001$, Sobel test: $z=$ $4.11, p<.001)$. In other words, and in accordance with Hypothesis 1, the link between racism and ordinary sexism was mediated by the idea that the Other is more sexist than the Swiss. The gender of the respondents did not moderate 
Table 2 Intercorrelations for all measures by gender.

\begin{tabular}{llllll}
\hline & 1 & 2 & 3 & 4 & 5 \\
\hline 1. Racism & - & $.394^{* *}$ & $.275^{* *}$ & $-.378^{* *}$ & -.012 \\
2. Ordinary sexism & $.377^{* *}$ & - & $.393^{* *}$ & $-.346^{* *}$ & -.025 \\
3. Sexism of the other & $.558^{* *}$ & $.402^{* *}$ & - & $-.316^{* *}$ & -.051 \\
4. Feminism & $-.292^{* *}$ & -.130 & $-.356^{* *}$ & - & .130 \\
5. Family sexism & $.241^{* *}$ & .130 & $.275^{* *}$ & .002 & - \\
\hline
\end{tabular}

this mediation and the mediation was significant when performed separately for women and men (women: $z=2.64$, $p<.01$; men: $z=2.60, p<.01$ ).

The Sexism of the Other: The Impact of Racism and Feminism

Hypothesis 2 states that the attribution of a higher level of sexism to the Other can be countered by simultaneously adopting both feminist and non-racist attitudes. In order to test this hypothesis, we analyzed the impact of the interaction between feminist and racist opinions on the evaluation of family sexism as a function of the experimental condition (African vs. Swiss family). We computed dichotomous variables of feminist attitudes (median split: 3.66) and racist attitudes (median split: 3.75); based on these variables, we created a "feminist/racist" typology by crossing the two attitudes. This typology resulted in four groups: the "feminist + and racist + " $(\mathrm{F}+\mathrm{R}+, n=58)$ group, the "feminist + and racist $-"(\mathrm{~F}+\mathrm{R}-, n=92)$ group, the "feminist-and racist + " $(\mathrm{F}-\mathrm{R}+, n=80)$ group, and the "feminist-and racist -" (F-R-, $n=42)$ group. An ANOVA was performed on the attribution of sexism to the family introducing the experimental variable (African family vs. Swiss family) and the "feminist/racist" typology as independent variables. In order to confirm Hypothesis 2, results should show that for the typology groups " $\mathrm{F}+\mathrm{R}+$," " $\mathrm{F}-\mathrm{R}+$," and " $\mathrm{F}-\mathrm{R}-$," the effect of the experimental condition is

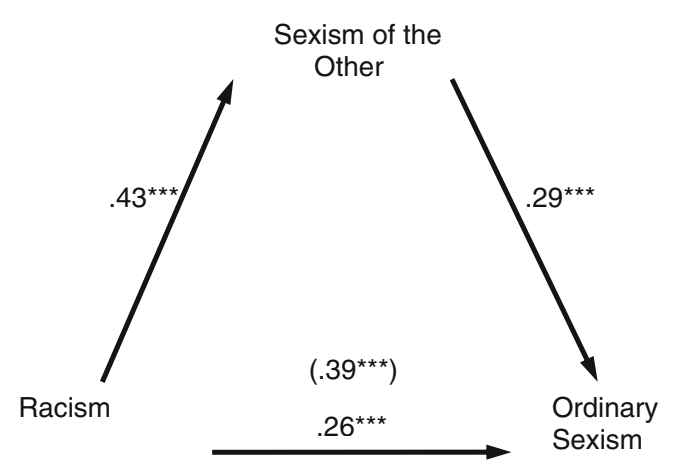

Fig. 1 Racism and ordinary sexism: the mediating role of the sexism of the Other (Standardized regression weights). Note. The value within parentheses indicates the relation between racism and sexism when the mediator was not included. $* * * p<.001$. significant: the family in the "Other" condition (the African family) should be perceived as more sexist than the family in the "national" condition (the Swiss family). In contrast, for the group " $\mathrm{F}+\mathrm{R}-$," the effect of the experimental condition should not be significant.

Results show a principal effect of the experimental condition: respondents attributed a higher level of sexism to the African family $(M=4.62)$ than to the Swiss family $(M=$ $4.13, F(1,271)=30.96, p<.001$, partial $\eta$ squared $=.105)$. The effect of the "feminist/racist" typology was also significant $(F$ $(3,271)=3.13, p<.05$, partial $\eta$ squared $=.034)$ and, as expected, the interaction between the experimental condition and the typology was significant $(F(3,271)=4.20, p<.01$, partial $\eta$ squared $=.046$ ). The decomposition of this interaction effect (see Fig. 2) shows that opinions about the sexism of the family were significantly different depending on the presumed origin of the family for three groups of participants $(\mathrm{F}-\mathrm{R}-: F(1,271)=7.80, p<.01 ; \mathrm{F}-\mathrm{R}+: F(1$, $271)=22.99, p<.001 ; \mathrm{F}+\mathrm{R}+: F(1,271)=8.65, p<.01)$, but not for the group classed as feminist and non-racist (F+R-, $F(1,271)=.12, n s)$. The gender of respondents had no impact on these results (i.e., no interaction effect was significant).

These results supported Hypothesis 2. Only the group of individuals who adopted an attitude that was both feminist and non-racist did not differentiate between Swiss and Other families regarding their perceived degree of sexism.

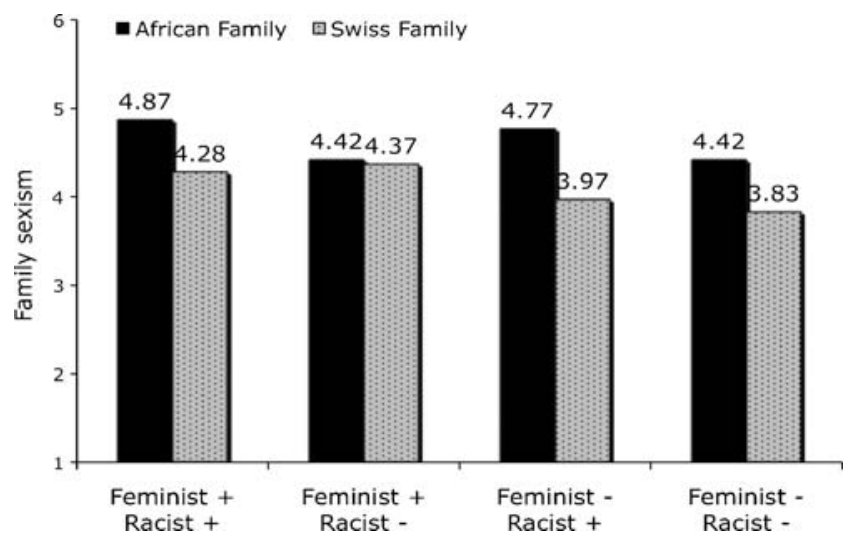

Fig. 2 Family sexism according to the vignette version (African family vs. Swiss family) and the "feminist/racist" typology. Note. 6point scale. 


\section{Discussion}

Consistent with Hypothesis 1, we demonstrated that the attribution of a higher level of sexism to the Other constitutes a racist process that contributes to the naturalization and justification of ordinary sexism. Highlighting the sexism of the Other, which is highly prevalent in the current political discourse regarding the difficulties of immigrant integration, risks reinforcing not only the domination of nationals over immigrants but also of males over females. The mediation was significant but only partial. The link between racism and ordinary sexism remains significant, possibly because racism and sexism are underlined by similar processes of division and hierarchization that cannot be reduced to the attribution of sexism to the Other.

As expected, men adhered more strongly to sexist beliefs and attributed a stronger degree of sexism to the Other compared to the Swiss than did women. These results suggest that men more strongly defend the existing gender system that places them in a dominant position; they defend their social advantage by naturalizing the gendered division of labor (ordinary sexism). Nevertheless, the full racist process leading to the attribution of a higher level of sexism to the Other and then to the naturalization and justification of ordinary sexism was not moderated by gender and appeared for both women and men.

Based on these results, we argue that the designation of foreigners as particularly sexist helps turn attention away from the fact that equality is an inalienable democratic value in principle, but not in reality. In this context, the denunciation of the sexism of immigrants is a process of Othering (Delphy 2008) that instrumentalizes gender equality (Roux et al. 2007) and consolidates relations of domination, whether they are founded on the criteria of race or of gender. On the one hand, in effect, the attribution of an extraordinary sexism to racialized groups locks them within an imposed Otherness from which it would seem justifiable to restrict their rights or to discriminate against them. On the other hand, the stigmatization of the Other, relegated to "his patriarchal culture," leads to the legitimization of the ordinary sexism of Western countries that is based on the naturalization and justification of the gendered division of labor (Guillaumin 1995).

Moreover, in line with Hypothesis 2, we have demonstrated that the same sexist act (forced marriage) is not interpreted in the same way depending on the national origin of the family in which it takes place. Only women and men who share both feminist and non-racist attitudes avoid hierarchizing the gravity of sexism according to the national origin of the participants. All forced marriages are condemned, to be sure, but some, more than others, evoke impressions of a particularly patriarchal family. Many participants considered an African Muslim family to be more sexist than a wealthy Swiss family, even when both were employing the very same sexist practice. Our finding supports the idea that to fight successfully for the liberation of all women, feminism must be coupled with an anti-racist sensibility (Delphy 2006) or an "intersectional political consciousness" (Greenwood 2008, p.38). This intersectional consciousness develops when a feminist consciousness is coupled with the consciousness of the privilege of being a member of the dominant ethnic group. In other words, our results suggest that feminists, when thinking about gender oppression, should think about racial and other forms of oppression as well (Delphy 2008).

\section{Parallels with Other Studies on Racism and Sexism}

We join other feminist scholars who adopt an intersectional approach (Collins 2000; Crenshaw 1994) to argue that, in order to improve the validity of studies of gender and race attitudes, it is important to pay attention to the fact that sexism against White women is structured by specific positions in the matrix of relations of domination (as is sexism against Black women). In the majority of studies, stereotypes toward "women" measure stereotypes toward White women, and, similarly, scales presented to measure general sexism are in fact scales of Western sexism. This reflects an ethnocentric bias in research in which knowledge about gender relations in a specific group (i.e., White people, the "referent," Guillaumin 1995) is considered to be "universal" knowledge about gender relations. Likewise, studies analyzing racism without paying attention to gender relations risk the production of an androcentric bias (see Steinbugler et al. 2006). Research presented in this paper provides supplementary evidence regarding the necessity of considering the multidimensionality and interlocking nature of hierarchical systems.

\section{Limitations and Directions for Future Research}

Although empirical evidence corroborated our hypotheses in this study, we must acknowledge some limitations. Our goal was to empirically test ideas developed in the tradition of feminist materialist sociology (Delphy 1984, 2008 and Guillaumin 1995) and linked to Black feminism and critical postcolonial studies. We therefore elaborated new measures, most notably addressing ordinary sexism and the sexism of the Other. In the future, it will be important to establish parallels between these measures and other scales of sexism (e.g., Swim et al. 1995) and to validate our measures in other national contexts and by using random samples. 
This study showed circumstances in which feminism and racism predict the denunciation of sexist practices that are usually attributed to Others. In order to draw a strict parallel between gender and race hierarchical systems, it will be important in future research to include anti-racism measures as well.

The vignettes were developed to show that, for the same sexist act, the racial positions of the perpetrators and the victims affect judgments about the sexism of the act. The results confirm our hypotheses, but we have to recognize that "forced marriage" is a practice that probably fits better with representations of the Other than with Western sexism. Results reported in Table 2 show that, for men, family sexism, regardless of the experimental condition, was correlated with racism and sexism of the Other while for women there were no significant correlations, which may suggest that this racialized representation of forced marriages could be stronger for men than for women. Nevertheless, the fact that the feminist and non-racist group did not differentiate between the two conditions gives us grounds to say that this was not a fundamental problem. However, it will be important in the future to replicate these results with a race-neutral practice.

One additional limitation emerges from the fact that we did not orthogonalize race and class concerns in the vignettes. We compared a wealthy Genevan family (dominant in race and class relations) to an African Muslim family (explicitly dominated only in race relations). We chose this option in order to dramatize a clearly dominant category as opposed to a heavily stigmatized racialized category in Switzerland. By making explicit reference to the favored social class of the Swiss family, we wanted to be sure that the participants could not attribute the marriage the family imposed upon their daughter to difficult life circumstances and that they would think of the family as in a socially dominant position. In this paper, we interpret the effect of the experimental condition as an interconnection between gender and race relations, but we cannot be sure if class concerns are not also at stake. Therefore, it will be important to orthogonalize these dimensions in the future. We can, for example, hypothesize that the same process of stigmatizing the Other can also take place in regards to other dominated groups, notably lower social classes. The sexism perceived "at home" could be considered to be a residue of archaic, "backward" gender relations attributed not only to immigrants, but also to lower social classes. The symbolic exclusion of certain members of the national intra-group would thus protect the normative power of the dominant model and legitimize the social hierarchy and differentiation between social groups. This suggestion opens the way to other studies that would show that the Other, accused of an extraordinary sexism, is not only racialized but is also "classed."

\section{Implications for Research and Application}

In conclusion, our study shows that the denunciation of the sexism of the Other does not automatically reflect a feminist position; it can also reflect a racist position consisting of the attribution of a devalued difference to the Other (he is too sexist) and resulting in the naturalization and justification of ordinary sexism. We showed that only when feminism and non-racism are associated do men and women denounce the sexism that takes place in the Occident and the sexism of the Other with the same force.

These results are important in a theoretical way by giving new input to the intersectional perspective and by proposing new results based on quantitative data that are complementary to the greater number of qualitative researches done within this perspective. Our analysis could also contribute to the improvement of experimental settings analyzing hierarchical relations that should more often take into account the multidimensionality and interlocking nature of hierarchical systems. In effect, results obtained with settings that manipulate only one hierarchical dimension, and observe the effects of the manipulation on this dimension solely, do not reflect all the facets of Othering processes and risk therefore to subtend general psychosocial or sociological theories that fit, in real settings, with some sub-groups only, generally the dominant ones. From a more applied perspective, our results contribute to the debate about the link between feminist and anti-racist struggles by showing that the connections between them are essential to fight efficiently against discrimination and exploitation.

Acknowledgement We would like to thank the editor of Sex Roles and two anonymous reviewers for their very helpful comments on previous versions of this article.

\section{Appendix A}

Racism Scale $(1=$ completely disagree to $6=$ completely agree $)$

In your opinion, why have certain immigrants in Switzerland had difficulty integrating themselves?:

1. Their values are too different from predominant Swiss values.

2. They don't make enough effort to integrate well.

3. They spend too much time amongst themselves, without seeking contact with people from different cultural backgrounds.

4. The cultural traditions of certain countries in the South and the East are poorly compatible with the prevalent lifestyles of most Europeans. 
Ordinary Sexism Scale $(1=$ completely disagree to $6=$ completely agree)

Numerous sociological studies have shown that it is predominantly women who care for children and households. What are the explanations, as you see it, for this situation?

1. It is because women bear children and give birth to them.

2. It is because women and men have different wishes, tastes, and interests.

3. It is because most men are less talented than women at housekeeping and the tasks related to child-rearing.

4. It is because it is more natural for a woman than for a man to take care of children and a household.

5. It is right that it should be more the role of men than of women to take care of the financial needs of a family.

6. It is right that it should be more the role of women than of men to take care of the household and children.

Feminism Scale $(1=$ no, not at all to $6=$ yes, completely $)$

1. In daily life, do you think you fight, in your own way, against inequalities between men and women?

2. Do you consider yourself a person with feminist convictions?

3. Are you ready to engage in feminist causes (for example, in a militant association, or as a participant in protests, etc.)?

Composed Measure (item 2 minus item 1) of Sexism of the Other $(1=$ completely disagree to $6=$ completely agree $)$

1. Sexism is still highly present in Switzerland. In this area we fail to go beyond principle declarations and concretize gender equality.

2. However, sexism is less strong in Switzerland than in other countries, notably the countries of the South (some African and Arab countries, for example).

Family Sexism Scale $(1=$ completely disagree to $6=$ completely agree)

In your opinion, if we compare this type of family to others, can we say that:

1. In this type of family, women are less emancipated than others

2. Men are more dominant and exert more control over "their" women (wife, daughters...) than other men.

3. Arranged or forced marriages are more common.
4. In this type of family, parents inculcate values into their children that are maladapted to those necessary to integrate well into the adult world.

\section{Appendix B: Original French Scales}

Echelle de racisme ( $1=$ pas du tout d'accord, $6=$ tout à fait d'accord)

A votre avis, pour quelles raisons certaines personnes immigrées en Suisse ont-elles des difficultés à s'intégrer?

1. Leurs valeurs sont trop différentes des valeurs dominantes en Suisse

2. Elles ne font pas assez d'efforts pour bien s'intégrer

3. Elles restent trop souvent entre elles, sans chercher le contact avec des personnes d'origine autre que la leur

4. Les traditions culturelles de certains pays du Sud et de l'Est sont difficilement compatibles avec le mode de vie qu'ont généralement les gens en Europe

Echelle de sexisme ordinaire $(1=$ pas du tout d'accord, $6=$ tout à fait d'accord)

Nombre d'enquêtes sociologiques mettent en évidence que ce sont surtout les femmes qui prennent en charge les enfants et le ménage. Quelles sont les raisons qui, selon vous, expliquent cette situation?

1. C'est parce que ce sont les femmes qui portent les enfants et les mettent au monde

2. C'est parce que les femmes et les hommes ont des envies, des goûts et des intérêts différents

3. C'est parce que la plupart des hommes sont moins doués que les femmes pour le ménage et les tâches liées aux enfants

4. C'est parce qu'il est plus naturel pour une femme que pour un homme de s'occuper des enfants et du ménage

5. Il est juste que ce soit plus le rôle des hommes que des femmes d'entretenir financièrement une famille

6. Il est juste que ce soit plus le rôle des femmes que des hommes de s'occuper du ménage et des enfants ».

Echelle de féminisme ( $1=$ non, pas du tout, $6=$ oui, tout à fait $)$

1. Dans la vie quotidienne, estimez-vous que vous luttez, à votre manière, contre les inégalités entre hommes et femmes ?

2. Vous considérez-vous comme une personne qui a des convictions féministes ? 
3. Etes-vous prêtee à vous engager pour des causes féministes (par exemple dans une association militante, ou en participant à des manifestations, etc.)?

Mesure composée (item 2 moins item 1) de sexisme de l'Autre ( $1=$ pas du tout d'accord, $6=$ tout à fait d'accord $)$

1. Le sexime en Suisse est toujours très présent. Dans ce domaine on a de la peine à dépasser les declarations de principe et à concrétiser l'égalité homes-femmes.

2. Toutefois, le sexisme est moins fort en Suisse que dans d'autres pays, du Sud notamment (certains pays africains et arabes par exemple).

Echelle du sexisme de la famille $(1=$ pas du tout d'accord, $6=$ tout à fait d'accord)

Si l'on compare ce type de famille à d'autres, peut-on dire, selon vous, que:

1. Dans ce type de famille, les femmes sont moins émancipées que les autres

2. Les hommes sont plus dominants et contrôlent davantage "leurs" femmes (épouse, filles...) que les autres hommes

3. Les mariages arrangés ou forcés sont plus courants

4. Dans ce type de famille, les parents inculquent à leurs enfants des valeurs mal adaptées à celles qui sont nécessaires pour bien s'intégrer dans le monde adulte

\section{Appendix C: Vignettes}

\section{African Family Version}

A child protection service in French-speaking Switzerland must manage the following case regarding an African family:

Fatou N. comes from a Muslim family with no previous history that has been living in Switzerland for 8 years. Without her parents' knowledge, Fatou had a fling with Ndongo, a 22-year-old man. Following a one-time sexual tryst with him, she finds herself pregnant, and must then tell her parents. They decide that she must marry the young man in question, although she has no wish whatsoever to do so. She is only 15 years old and cannot imagine spending her life with a man she hardly knows.

\section{Swiss Family Version}

A child protection service in French-speaking Switzerland must manage the following case regarding a family from Geneva:

Jeanne N. comes from a relatively wealthy family with no previous history. Without her parents' knowledge, Jeanne had a fling with Patrick, a 22-year-old man. Following a one-time sexual tryst with him, she finds herself pregnant, and must then tell her parents. They decide that she must marry the young man in question, although she has no wish whatsoever to do so. She is only 15 years old and cannot imagine spending her life with a man she hardly knows.

\section{References}

Baron, R. M., \& Kenny, D. A. (1986). The moderator-mediator variable distinction in social psychological research: Conceptual, strategic and statistical considerations. Journal of Personality and Social Psychology, 51, 1173-1182.

Buckley, T. R., \& Carter, R. T. (2005). Black adolescent girls: Do gender role and racial identity impact their self-esteem? Sex Roles: A Journal of Research, 53, 647-661.

Bülent, K. (2005). Switzerland. In J. Niessen, Y. Schibel, \& R. Magoni (Eds.), Current immigration debates in Europe. Brussels: MPG.

Campbell, B., Schellenberg, E. G., \& Senn, C. Y. (1997). Valuating measures of contemporary sexism. Psychology of Women Quarterly, 21, 89-102.

Collins, P. H. (2000). Black feminist thought: Knowledge, consciousness and the politicsof empowerment (2nd ed.). New York: Routledge.

Combahee River Collective. (1979). Collective statement. In Z. Eisenstein (Ed.), Capitalist patriarchy and the case for socialist feminism (pp. 362-372). New York: Monthly Review Press.

Crenshaw, K. W. (1994). Mapping the margins: Intersectionality, identity politics, and violence against women. In M. A. Fineman \& R. Mykitiuk (Eds.), The public nature of private violence (pp. 93-120). New York: Routledge.

Crosby, F. J., Iyer, A., \& Sincharoen, S. (2006). Understanding affirmative action. Annual Review of Psychology, 57, 585-611.

Delphy, C. (1984). Close to home. A material analysis of women's oppression. London: Hutchinson.

Delphy, C. (2001). L'ennemi principal. Tome 2: Penser le genre [The greatest enemy. Vol 2: Thinking gender]. Paris: Syllepse.

Delphy, C. (2006). Antisexisme ou antiracisme? Un faux dilemme [Anti-sexism or anti-racism? A false dilemma]. Nouvelles Questions Féministes, 25, 59-83.

Delphy, C. (2008). Classer, dominer. Qui sont "les autres"? [Classify, dominate. Who are "the others"?]. Paris: La fabrique.

Giugni, M., \& Passy, F. (2006). La citoyenneté en débat. Mobilisations politiques en France et en Suisse [Citizenship on debate. Political mobilization in France and Switzerland]. Paris: L'Harmattan.

Glick, P., \& Fiske, S. T. (2001). An ambivalent alliance: Hostile and benevolent sexism as complementary justifications for gender inequality. American Psychologist, 56, 109-188.

Greenwood, R. M. (2008). Intersectional political consciousness: appreciation for intragroup differences and solidarity in diverse groups. Psychology of Women Quarterly, 32, 36-57.

Greenwood, R. M., \& Christian, A. (2008). What happens when we unpack the invisible knapsack? Intersectional political consciousness 
and inter-group appraisals. Sex Roles: A Journal of Research, 59, $404-417$.

Guillaumin, C. (1972). L'idéologie raciste. Genèse et langage actuel [The racist ideology. Genesis and actual language]. Paris: Gallimard.

Guillaumin, C. (1995). Racism, sexism, power and ideology. New York: Routledge.

Hamel, C. (2003). 'Faire tourner les Meufs': Les viols collectifs dans les discours des agresseurs et des medias ['Faire tourner les Meufs': collectives rapes in aggressor and media discourse]. Gradhiva, 33, 85-92.

Hooks, B. (1981). Ain't I a woman: Black women and feminism. Boston: South End Press.

Hull, G. T., Bell Scott, P., \& Smith, B. (Eds.). (1982). All the women are white, all the blacks are men, but some of us are brave. Black women's studies. Pld Westbury: Feminist Press.

Hurtig, M.-C., \& Pichevin, M.-F. (1991). Catégorisation de sexe et perception d'autrui [Sex categorization and the perception of the other]. In M.-C. Hurtig, M. Kail, \& H. Rouch (Eds.), Sexe et genre. De la hiérarchie entre les sexes (pp. 169-180). Paris: CNRS.

Jenson, J., Laufer, J., \& Maruani, M. (Eds.). (2000). The gendering of inequalities: Women, men and work. New York: Ashgate.

Mathieu, N.-C. (2000). Sexe et genre [Sex and gender]. In H. Hirata, F. Laborie, H. Le Doaré, \& D. Senotier (Eds.), Dictionnaire critique du féminisme (pp. 191-200). Paris: Presses Universitaires de France.

Morraga, C., \& Anzaldua, G. (Eds.). (1983). This bridge called My Back: Writings by radical women of color. New York: Kitchen Table Women of Color Press.

Nader, L. (1989). Orientalism, occidentalism and the control of women. Cultural Dynamics, 2, 323-355.

Pettigrew, T. F., \& Meertens, R. W. (1993). Le racisme voilé: dimensions et mesures [Subtle racism: dimensions and measures]. In M. Wieviorka (Ed.), Racisme et modernité (pp. 109126). Paris: La découverte.

Pettigrew, T. F., \& Meertens, R. W. (1995). Subtle and blatant prejudice in Western Europe. European Journal of Social Psychology, 25, 57-75.

Purdie-Vaughns, V., \& Eibach, R. P. (2008). Intersectional invisibility: The distinctive advantages and disadvantages of multiple subordinategroup identities. Sex Roles: A Journal of Research, 59, 377-391.

Reid, P. T., \& Comas-Diaz, L. (1990). Gender and ethnicity: Perspectives in dual status. Sex Roles: A Journal of Research, 22, 397-408.

Roux, P. (2008). Conceptions profanes de la division sexuelle du travail [Lay thinking on the gendered division of labor]. In M.
Rosende \& N. Benelli (Eds.), Laboratoires du travail (pp. 117128). Lausanne: Antipodes.

Roux, P., \& in collaboration with Perrin, V., Modak, M., \& Voutat, B. (1999). Couple et égalité: un ménage impossible [Couples and equality: a contradiction in terms]. Lausanne: Réalités sociales.

Roux, P., Gianettoni, L., \& Perrin, C. (2006). Féminisme et racisme. Une recherche exploratoire sur les fondements des divergences relatives au port du foulard [Feminism and racism: an exploratory research on feminist divergences about Muslim handcraft]. Nouvelles Questions Féministes, 25(1), 84-106.

Roux, P., Gianettoni, L., \& Perrin, C. (2007). L'instrumentalisation du genre: une nouvelle forme de racisme et de sexisme [Gender instrumentalization: A new form of racism and sexism]. Nouvelles Questions Féministes, 26(2), 92-108.

Settles, I. H. (2006). Use of an intersectional framework to understand black women's racial and gender identities. Sex Roles: A Journal of Research, 54, 589-601.

Staerklé, C., Delay, C., Gianettoni, L., \& Roux, P. (2007). Qui a droit à quoi ? Représentations et légitimation de l'ordre social ["Qui a droit à quoi?» Representation and légitimation of the social order]. Grenoble: PUG.

Steinbugler, A. C., Press, J. E., \& Dias, J. J. (2006). Gender, race, and affirmative action: Operationalizing intersectionality in survey research. Gender \& Society, 20, 805-825.

Stolcke, V. (1995). Talking culture. New boundaries, new rethorics of exclusion in Europe. Current Anthropology, 36(1), 1-24.

Stolz, J. (2005). Explaining islamophobia. A test of four theories based on the case of Swiss City. Swiss Journal of Sociology, 31, 547-566.

Swim, J. K., Aikin, K. J., Hall, W. S., \& Hunter, B. A. (1995). Sexism and racism: Old-fashioned and modern prejudices. Journal of Personality and Social Psychology, 68, 199-214.

Swiss Federal Statistical Office. (2008). On the way to gender equality. Current situation and developments. SFSO: Neuchâtel.

Tajfel, H. (1978). Social categorization, social identity and social comparison. In H. Tajfel (Ed.), Differentiation between social groups. New York: Academic Press.

Volpp, L. (2000). Blaming culture for bad behavior. Yale Journal of Law and the Humanities, XII(89), 89-116.

West, C., \& Zimmerman, D. H. (1998). Doing gender. In K. A. Myers, B. J. Risman, \& C. D. Anderson (Eds.), Feminist foundations: Toward transforming sociology (pp. 167-190). Thousand Oaks: Sage Publications.

Wicker, H.-R., Fibbi, R., \& Haug, W. (Eds.). (2003). Les migrations et la Suisse. Résultats du Programme national de recherche "Migrations et relations interculturelles» [Migrations in Switzerland: Results of the national research program]. Zurich: Seismo. 